\title{
Investigating the Frequency of Candida glabrata in Diabetic Women of Tehran with Recurrent and Non-recurrent Vulvovaginal Candidiasis Using PCR-RFLP Assay
}

\author{
Mansoureh Paknejadi ${ }^{1}$, Mansour Bayat ${ }^{*}$, Vadood Razavilar ${ }^{1}$ \\ ${ }^{1}$ Department of Pathobiology, Science and Research Branch, Islamic Azad University, Tehran, Iran
}

Received Jul. 23, 2019; Accepted Sep. 16, 2019

\begin{abstract}
Introduction: Vulvovaginal Candidiasis (VVC) is one of the most common genital tract infections among women, especially in diabetic patients. The increasing prevalence of recurrent infections caused by drug-resistant non-albicans species necessitates further studies on diabetic patients and the identification of causative agents by reliable molecular techniques. The obtained results can assist in adopting proper treatment procedures and prevention of recurrent vulvovaginitis (RVVC). Methods: In a cross-sectional study, 150 vaginal discharge samples were collected from diabetic women suspected of candidiasis referring to health centers in Tehran province. Following the culture of samples on SDA, CHROMagar Candida and PCR-RFLP were used for presumptive and definitive identification of Candida species, respectively. Results: Out of 115 positive patients, 105 showed infection with one species, and 10 had a mixed infection with two species. The frequency of Candida glabrata isolated from non-mixed and mixed infections in RVVC group was higher than Candida albicans (27.8\% vs. 9.6\%), which contradicted the results of the VVC group $(6.1 \%$ vs. $24.3 \%)$. In the RVVC group, therefore, the patients were more infected with nonalbicans species than C. albicans ( $47.8 \%$ vs. $9.6 \%$ ), while in the VVC group the non-albicans were of lower frequency $(18.3 \%$ vs. $24.3 \%)$. Conclusion: Our findings showed a statistically significant correlation $(P<0.001)$ between the frequency of $C$. glabrata and the prevalence of RVVC. On the other hand, that blood sugar, duration of diabetes, and antibiotics usage had significant correlations $(P<0.001)$ with the recurrence of severe symptoms. J Med Microbiol Infec Dis, 2019, 7 (1-2): 44-51.
\end{abstract}

Keywords: Candida glabrata, Diabetes Mellitus, Polymerase Chain Reaction, Vulvovaginal candidiasis, Iran.

\section{INTRODUCTION}

Vaginitis is one of the most prevalent reproductive tract infections (RTIs) among sexually active women. Annually, about 340 million cases of curable sexually transmitted infections (STIs) occur worldwide, mostly in developing countries $[1,2]$. After bacterial infections, vulvovaginal candidiasis is believed to be responsible for approximately one-third of vaginitis cases [3, 4]. However, some studies indicate a higher prevalence of Candida infection compared to bacterial vaginosis and trichomoniasis [5, 6, 7]. About $\% 75$ of healthy women within the age range of 25 50 years have experienced non-recurrent vulvovaginal candidiasis (VVC) at least once in their lifetime, but $5 \%$ to $20 \%$ are prone to recurrent vulvovaginal candidiasis (RVVC) at least four times during a year [7-9].

Candida species are part of normal flora in the skin, mucous membranes, and gastrointestinal tract; however, in the presence of predisposing factors, they can appear as an opportunistic agent causing severe infections. The most critical predisposing factors include immunosuppressive diseases, uncontrolled diabetes, high carbohydrate diet, pregnancy, lack of personal hygiene, estrogen contraceptives, high sexual activity or high-risk behaviors, prescription of improper drug, self-treatment and prolonged use of broad-spectrum antibiotics and corticosteroids, incomplete or extended use of antimycotics, and resistance of Candida species to azoles [10-13]. Diabetes mellitus $(\mathrm{DM})$ is one of the major risk factors for severe infections caused by different Candida species. Women with VVC and DM, particularly those with poorly controlled hyperglycemia, are prone to develop RVVC caused by nonalbicans Candida (NAC) species [14-16]. Non-recurrent vulvovaginal candidiasis is an uncomplicated and mild disease which is mainly prevalent among healthy women infected with Candida albicans, while recurrent VVC is a complicated and more severe disease often caused by drugresistant NAC species in immunocompromised women [1416]. Candida albicans is known as the primary cause of vulvovaginal candidiasis, however; today, NAC species, especially $C$. glabrata, which is intrinsically resistant to a vast range of azoles and antifungal compounds are on the

\footnotetext{
*Correspondence: Mansour Bayat

Department of Pathobiology, Science and Research Branch, Islamic Azad University, Tehran, Iran, 1477893855.
}

Email: m.bayat@srbiau.ac.ir

Tel: +98 (21) $44865154 \quad$ Fax: +98 (21) 44865167 
increase. Some studies have estimated that $\% 15$ to $\% 47$ of RVVC cases were caused by $C$. glabrata, which is a major cause of treatment-resistant severe infections worldwide $[11,12,17]$.

The accurate diagnosis of the causative agent of infection can be helpful in timely appropriate treatment of vulvovaginal candidiasis. Due to the similar clinical symptoms (e.g., pruritus, inflammation and irritation of vulva and vagina, and smelly discharges) in vulvovaginitis caused by Trichomonas vaginalis, bacteria and Candida spp., clinical examinations, and routine microbial procedures are not very reliable for identification of the real causative agent $[1,18-21]$. Therefore, the use of precise and specific molecular techniques such as PCR-RFLP, RealTime qRT-PCR, RAPD-PCR, multiplex-PCR can be useful for solving diagnostic limitations. Many researchers have introduced PCR-RFLP as a reliable and cost-effective method for rapid recognition of Candida species in research centers and diagnostic laboratories [18-22].

Regarding the increasing prevalence of $C$. glabrata, and limited studies on diabetic women, we prompted to investigate the frequency of this species in two groups of diabetic patients with VVC and RVVC using the PCRRFLP technique. Besides, the association between recurrence of infection symptoms with some important predisposing factors such as blood sugar, duration of diabetes, and antibiotics usage was evaluated.

\section{MATERIAL AND METHODS}

Sample collection and culture. In a cross-sectional study, we investigated 150 diabetic patients referring to several gynecologic clinics in the province of Tehran from April 2015 to September 2017. The inclusion criteria for the study included married non-pregnant women aged 25 to 45 year old with at least high school education, diabetes mellitus, and not being on corticosteroids and steroid contraceptives. The patients showed mild to severe vulvovaginal symptoms, e.g. inflammation, irritation, erythema, fissures, pruritus, dyspareunia, and smelly whiteyellow discharges. They were divided into two groups: women with recurrent infection (at least 3 to 4 recurrent infection during one year) and those with a non-recurrent infection. Informed consent was obtained from all participants or their guardians, and the ethical committee of the Islamic Azad University of Science and Research Branch (Tehran) approved the study (code: 131339).

Vaginal discharges were obtained using two sterile swabs by gynecologists and immediately stored in Falcon tubes containing sterilized PBS. The clinical specimens were transferred to the university laboratory. The vaginal discharge from one of the swabs was mixed with a drop of PBS, spread on a clean glass slide and covered with a coverslip, and examined for yeast cells under a microscopic with 100x magnification. Another swab was used for culture on Sabouroad's dextrose agar (SDA, Merck KgaA Darmstadt Germany) supplemented with chloramphenicol followed by incubation at $37^{\circ} \mathrm{C}$ for $24-48 \mathrm{~h}$. All newlygrown colonies were cultured on CHROMagar Candida (CHROMagar, France) at $37^{\circ} \mathrm{C}$ for $48-72 \mathrm{~h}$. The initial identification of Candida species was performed based on color and surface characteristics of colonies (glossy or dry) [1, 13, 18-20]. Candida glabrata (ATCC90030) and Candida albicans (ATCC10231) were included as controls in the study.

DNA extraction and PCR. Extraction of genomic DNA was performed by a DNP ${ }^{\mathrm{TM}}$ kit (Sinaclon, Iran) according to the manufacturer's instruction. The extracted DNAs were stored at $-20^{\circ} \mathrm{C}$ until used. The ribosomal DNA (ITS1, ITS2, and 5.8 S rRNA gene) of Candida species were amplified by universal fungal primers (ITS-1:5'TCCGTAGGTGAACCTGCGG-3'and ITS-4:5'-TCCTCCGCTTATTGATAT GC-3') [20-22].

PCR mixture was prepared according to the instruction for the Taq 2X Master Mix RED (Ampliqon, Denmark). The reaction included $12.5 \mu \mathrm{l} 2 \mathrm{X}$ Master Mix RED, $2 \mu 1$ DNA, 10 pmol of each primer, and molecular grade $\mathrm{dH}_{2} \mathrm{O}$ (Thermo Scientific, Lithuania) to the $25 \mu \mathrm{l}$ final volume. The thermal cycler (Technogen, United Kingdom) was programmed for an initial denaturation at $95^{\circ} \mathrm{C}$ for $5 \mathrm{~min}$ followed by 30 cycles of denaturation at $95^{\circ} \mathrm{C}$ for $30 \mathrm{~s}$, annealing at $56^{\circ} \mathrm{C}$ for $30 \mathrm{~s}$, and extension at $72^{\circ} \mathrm{C}$ for $60 \mathrm{~s}$, and a final extension at $72^{\circ} \mathrm{C}$ for $5 \mathrm{~min}$.

RFLP. Digestion of the amplicons was performed with MspI and AvrII (BlnI) enzymes (Thermo Scientific, Lithuania) according to manufacture's instruction. The 31 $\mu 1$ digestion reactions contained $1 \mu$ digestion enzyme (MspI or AvrII), $2 \mu \mathrm{l}$ digestion buffer, $10 \mu \mathrm{l}$ PCR product, and molecular grade $\mathrm{dH}_{2} \mathrm{O}$ to the final volume followed by incubation at $37^{\circ} \mathrm{C}$ for $3 \mathrm{~h}$.

Electrophoresis. The products obtained from three steps, i.e., DNA extraction, PCR, and digestion with restriction enzymes were resolved by electrophoresis on $1.8 \%$ agarose gels (Sinaclon, Iran) stained with $0.5 \mu \mathrm{l} / \mathrm{ml}$ of ethidium bromide (Sigma-Aldrich, Germany). The bands were visualized by UV light using a Gel documentation instrument (Lourmat-VX2 Viber, Germany), photographed, and interpreted accordingly authentic and standard data.

Statistical analysis. The statistical results were analyzed using SPSS version 19 software; $P$-values $<0.05$ were considered statistically significant. Data was presented in terms of numbers and percentages. Comparison between the results of two patient groups was performed using chisquare $\left(X^{2}\right)$ test, correlation, and independent t-test.

\section{RESULTS}

SDA culture and microscopy. Culture of vaginal samples on SDA medium containing chloramphenicol (Fig. 1A) and microscopic examination showed that out of 150 samples collected from diabetic women suspected of vulvovaginitis, $115(76.7 \%)$ were positive for fungal infection, while 35 (23.3\%) showed no infection. Based on the severity and recurrence of clinical manifestations (at least three recurrent infections in a year), 66 patients (57.4\%) were identified as RVVC group and $49(42.6 \%)$ as VVC.

CHROMagar Candida culture. For identification of Candida species, the colonies grown on CHROMagar 
Candida medium were evaluated based on color and surface characteristics of colonies such as being glossy or dry (Fig. 1B, C, and D).

We had difficulty in distinguishing the pale to dark pink/purple colonies of $C$. glabrata from other species producing similar colors such as Candida krusei, Candida guillermondii, and Candida kefyr, particularly in mixed
Candida infection. This problem was also observed to differentiate the light to dark green colonies of $C$. albicans from Candida dubliniensis.

PCR-RFLP. PCR amplification of the ribosomal DNA (ITS1, ITS2, and 5.8 S rRNA gene) region yielded bands of $510 \mathrm{bp}$ to $871 \mathrm{bp}$ size (Table 1$)$.
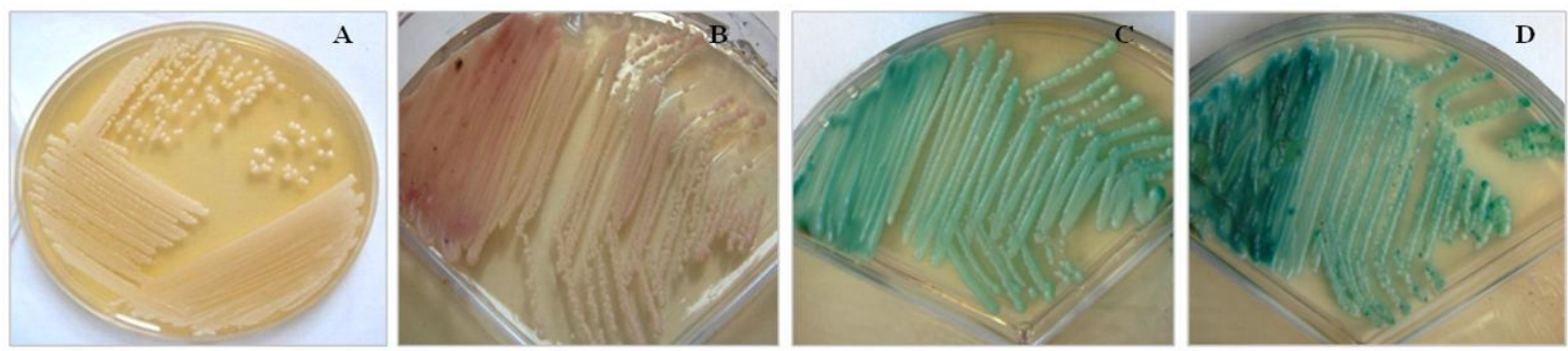

Fig. 1. Isolation and identification of Candida species by culture method. (A) Colonies of Candida spp. on Sabouroad's dextrose agar containing chloramphenicol, (B, C, and D). Colonies of Candida spp. on CHROMagar Candida medium. (B) C. glabrata, (C) C. albicans, and (D) C. dubliniensis

Table 1. Characteristics of the colonies of Candida species on CHROMagar Candida medium, the size of PCR-amplified ITS sequence, and fragments obtained following digestion with restriction enzymes

\begin{tabular}{|c|c|c|c|c|}
\hline \multirow{2}{*}{ Candida species } & \multirow{2}{*}{$\begin{array}{l}\text { Colony Characteristics on CHROMagar Candida } \\
\text { medium }\end{array}$} & \multirow{2}{*}{$\begin{array}{l}\text { Size of ITS1-ITS4 } \\
\text { (bp) }\end{array}$} & \multicolumn{2}{|c|}{ Size(s) of restriction enzyme products (bp) } \\
\hline & & & $M s p I$ & AvrII \\
\hline C. albicans & Light or dark green & 535 & $238-297$ & 535 \\
\hline C. dubliniensis & Dark green & 535 & $238-297$ & $200-335$ \\
\hline C. glabrata & Pale or dark pink/purple, glossy colonies & 871 & $314-557$ & NP* \\
\hline C. tropicalis & Dark bluish purple with light purple edges & 524 & $184-340$ & NP \\
\hline C. krusei & Rose pink, dry surface with whitish edges & 510 & $249-261$ & NP \\
\hline C. kefyr & Light or gray pink & 721 & 721 & NP \\
\hline C. guilliermondii & Violet or mauve lavender & 608 & $371-155-82$ & NP \\
\hline
\end{tabular}

*NP, Not performed

PCR identified the species C. guilliermondii, C. kefyr, and C. glabrata by amplification of definitive bands of 608 bp, $721 \mathrm{bp}$, and $871 \mathrm{bp}$ sizes, respectively (Fig. $2 \mathrm{~A}, \mathrm{~B}$, and C). However, it yielded amplicons of almost similar size for C. krusei $(510 \mathrm{bp}), C$. tropicalis $(524 \mathrm{bp})$, and $C$. albicans/C. dubliniensis (535 bp). RFLP analysis by MspI, which cut the DNA at CCGC sequence, created two bands for C. albicans/C. dubliniensis, C. glabrata, C. tropicalis, and $C$. krusei, and three bands for $C$. guillermondii.
However, digestion with MspI revealed a band of $721 \mathrm{bp}$ that was equal to the size of PCR-amplified ITS for C. kefyr. In addition to amplification of bands of similar size in $C$. albicans and $C$. dubliniensis by PCR, the MspI enzyme also produced similar bands in these two species. However, AvrII enzyme which cut CCTAGG sequence produced two definitive bands of $200 \mathrm{bp}$ and $335 \mathrm{bp}$ for $C$. dubliniensis (Table 1, Fig. 3 A, B, C, and D).
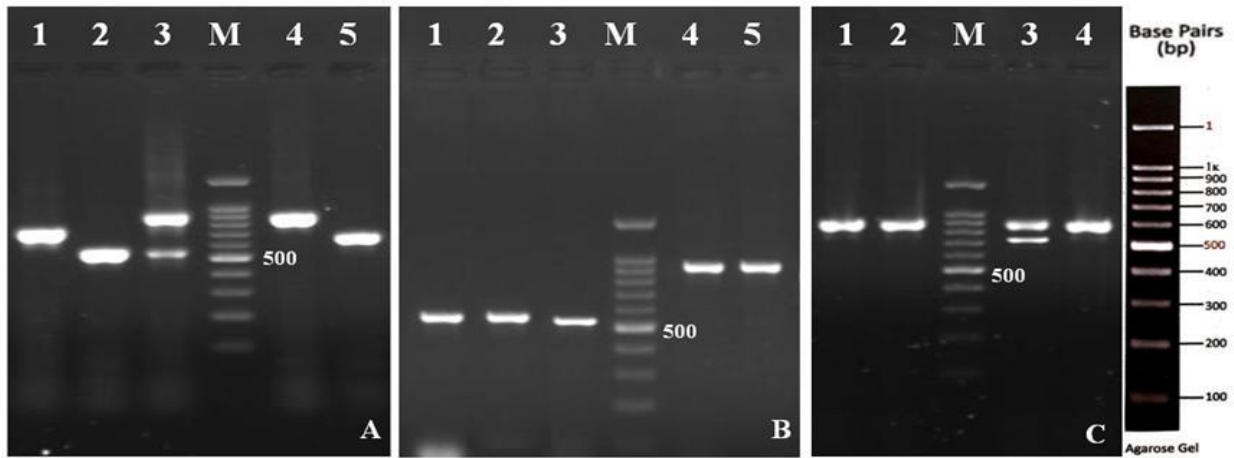

Fig. 2. Gel electrophoresis of PCR-amplified ITS sequences of Candida species. A) Lane 1, C. kefyr; lane 2, C. krusei; lane 3, C. glabrata and C. krusei; lane 4, C. glabrata and lane 5, C. guilliermondii. B) Lane 1, C. albicans (ATCC 10231); lane 2, C. albicans or C. dubliniensis; lane 3, C. tropicalis; lane 4, C. glabrata and lane 5, C. glabrata (ATCC 90030). C) Lanes 1 and 2, C. glabrata; lane 3, C. glabrata and C. kefyr and lane 4, C. glabrata (ATCC 90030). M, 100 bp ladder molecular size marker 

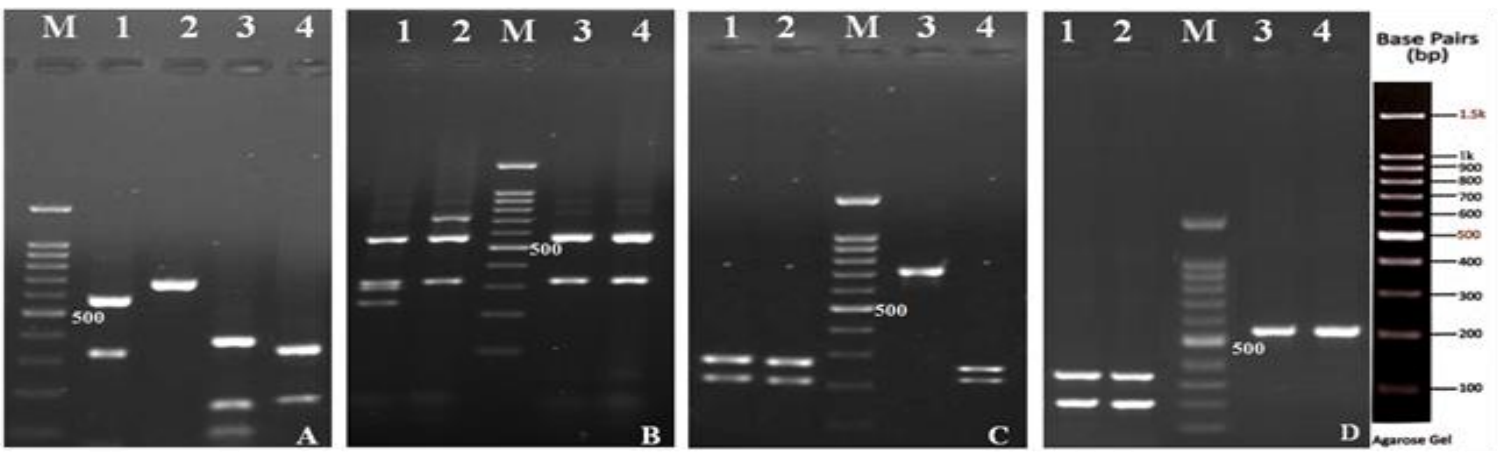

Fig. 3. RFLP pattern following digestion with $M s p \mathrm{I}$ (A-C) and AvrII (D) enzymes. A) lane 1, C. glabrata; lane 2, C. kefyr; lane 3, C. guilliermondii and lane 4, C. tropicalis. B) Lane 1, C. glabrata and C. krusei; lane 2, C. glabrata and C. kefyr; lane 3, C. glabrata and lane 4, C. glabrata (ATCC 90030). C) Lane 1, C. albicans (ATCC10231); lane 2, C. albicans or C. dubliniensis; lane 3, C. kefyr and lane 4, C. krusei. D) Lanes 1 and 2, C. dubliniensis; lane 2, C. albicans and lane 3, C. albicans (ATCC 10231). M,100 bp ladder molecular size marker

PCR-RFLP results showed that out of 115 patients, 105 including 47 with VVC and 58 with RVVC were infected with one Candida species, and 10 patients including 2 with
VVC and 8 with RVVC had infection two species (Tables 2 and 3).

Table 2. Absolute and relative frequency of Candida species in patients with vulvovaginal candidiasis

\begin{tabular}{|c|c|c|c|c|c|c|c|c|c|}
\hline $\begin{array}{l}\text { Type of } \\
\text { disease }\end{array}$ & $\begin{array}{l}\text { C. glabrata } \\
\text { No }(\%)\end{array}$ & $\begin{array}{l}\text { C. krusei } \\
\text { No }(\%)\end{array}$ & $\begin{array}{l}\text { C. kefyr } \\
\text { No }(\%)\end{array}$ & $\begin{array}{l}\text { C. tropicalis } \\
\text { No }(\%)\end{array}$ & $\begin{array}{l}\text { C.dubliniens } \\
\text { is No }(\%)\end{array}$ & $\begin{array}{l}\text { C.guilliermo } \\
\text { ndii No }(\%)\end{array}$ & $\begin{array}{l}\text { Total non-albicans } \\
\text { species No }(\%)\end{array}$ & $\begin{array}{l}\text { C. albicans } \\
\text { No }(\%)\end{array}$ & $\begin{array}{l}\text { Total } \\
\text { species } \\
\text { No }(\%)\end{array}$ \\
\hline RVVC $^{1}$ & 24 (20.9) & $7(6.1)$ & $5(4.3)$ & $6(5.2)$ & $4(3.5)$ & $1(0.9)$ & 47 (40.9) & $11(9.5)$ & $58(50.4)$ \\
\hline $\mathrm{VVC}^{2}$ & $5(4.3)$ & $4(3.5)$ & $4(3.5)$ & $3(2.6)$ & $3(2.6)$ & $0(0.0)$ & $19(16.5)$ & $28(24.4)$ & $47(40.9)$ \\
\hline Total & $29(25.2)$ & $11(9.6)$ & $9(7.8)$ & $9(7.8)$ & $7(6.1)$ & $1(0.9)$ & $66(57.4)$ & 39 (33.9) & $105(91.3)$ \\
\hline
\end{tabular}

${ }^{1}$ Recurrent vulvovaginal candidiasis

${ }^{2}$ Non-recurrent vulvovaginal candidiasis

Table 3. Absolute and relative frequency of mixed infections in patients with vulvovaginal candidiasis

\begin{tabular}{|c|c|c|c|}
\hline Type of disease & $\begin{array}{l}\text { C. glabrata+C. krusei } \\
\text { No }(\%)\end{array}$ & $\begin{array}{l}\text { C. glabrata+C. kefyr } \\
\text { No }(\%)\end{array}$ & $\begin{array}{l}\text { Total species } \\
\text { No }(\boldsymbol{\%})\end{array}$ \\
\hline $\mathrm{RVVC}^{1}$ & $5(4.4)$ & $3(2.6)$ & $8(7.0)$ \\
\hline $\mathrm{VVC}^{2}$ & $0(0.0)$ & $2(1.7)$ & $2(1.7)$ \\
\hline Total & $3(2.6)$ & $7(6.1)$ & $10(8.7)$ \\
\hline
\end{tabular}

${ }^{1}$ RVVC: Recurrent vulvovaginal candidiasis

${ }^{2}$ VVC: Non-recurrent vulvovaginal candidiasis

In RVVC group, the number of patients with nonalbicans species to $C$. albicans was 55 vs. 11 cases, while in the VVC group the number of them was 21 vs. 28 cases (Table 4). Based on the chi-square test $\left(\chi^{2}=20.557 ; d f=1\right.$; $P<0.001)$ and Spearman's correlation $(\rho=0.423 ; P<0.001)$ our results indicated a significant relationship between NAC species and the severity of the fungal infection $\left(P_{\text {Chi-square }}<0.001, \rho=0.4 ; P_{\text {Spearman }}<0.001\right)$. The frequency of C. glabrata was higher than other NAC species in both groups and even higher than $C$. albicans in the RVVC group. In fact, in the RVVC group, the number of total isolated $C$. glabrata from patients with mixed and nonmixed infection to $C$. albicans was 32 vs. 11 , while in the VVC group was 7 vs. 28. There was a significant association between $C$. glabrata frequency and incidence of recurrent vulvovaginal candidiasis $\left(P_{\text {Chi-square }}<0.001, \rho=0.5\right.$; $P_{\text {Spearman }}<0.001$; Tables 2, 3, and 4).

The participants' age ranged from 25 to 45 years. No significant difference was between the mean age of the two groups $\left(\mathrm{RVVC}=36.4 \pm 5.6 \mathrm{vs}\right.$. $\left.\mathrm{VVC}=35.0 \pm 5.5, P_{t \text {-test }}=0.195\right)$. The association between age and disease incidence was not statistically $\quad$ significant $\quad\left(P_{\text {Chi-square }}=0.276, \quad \rho=0.1\right.$; $P_{\text {Spearman }}=0.2$; Table 4$)$. The incidence of infection also showed no significant association with the educational status of participants $\left(P_{\text {Chi-square }}=0.547, \quad \rho=-0.03\right.$; $\left.P_{\text {Spearman }}=0.800\right)$. Nevertheless, the negative correlation coefficient indicates that an inverse correlation may exist between these variables (Table 4).

The results illustrated that the FBS levels could be significantly related to the incidence of infection in the RVVC group $\left(P_{\text {Chi-square }}<0.001, \rho=0.8 ; P_{\text {Spearman }}<0.001\right)$. The mean FBS level was also significantly higher in the RVVC than the VVC group $\left(322.0 \pm 91.2\right.$ vs. $166.0 \pm 29.5, P_{t}$. test $<0.001$ ). There was also a significant positive association between diabetes duration and recurrence of severe fungal infection $\left(P_{\text {Chi-square }}<0.001, \rho=0.6 ; P_{\text {Spearman }}<0.001\right)$. The mean duration of diabetes was significantly higher in the RVVC group than the VVC $\left(10.6 \pm 5.7\right.$ vs. $4.0 \pm 2.1, P_{t \text {-test }}$ $<0.001)$. We also found a significant positive association between antibiotic use and RVVC incidence $\left(P_{\text {Chi- }}\right.$ square $<0.001, \rho=0.7 ; P_{\text {Spearman }}<0.001$; Table 4$)$. 
Table 4. Distribution of samples according to the parameters and type of vulvovaginal candidiasis

\begin{tabular}{|c|c|c|c|c|}
\hline Variables & RVVC & VVC & Statistics data & $P$-Value \\
\hline Total number of patients with vulvovaginitis & $66(57.4)^{\mathrm{a}}$ & 49 (42.6) & - & - \\
\hline $\begin{array}{l}\text { Number of patients with NAC species (mixed \& non-mixed) } \\
\text { vs. } \text { C. albicans }\end{array}$ & $\begin{array}{l}55(47.8) \text { vs. } \\
\quad 11(9.6)\end{array}$ & $\begin{array}{l}21(18.3) \text { vs. } \\
28(24.3)\end{array}$ & $\begin{aligned} \chi^{2} & =20.557^{\mathrm{b}} \\
\rho & =0.423^{\mathrm{c}}\end{aligned}$ & $\begin{array}{l}<0.001 \\
<0.001\end{array}$ \\
\hline $\begin{array}{l}\text { Total number of } C \text {. glabrata isolated from mixed \& non- } \\
\text { mixed samples vs. } C \text {. albicans }\end{array}$ & $\begin{array}{c}32(27.8) \text { vs. } \\
\quad 11(9.6)\end{array}$ & $\begin{array}{l}7(6.1) \text { vs. } \\
28(24.3)\end{array}$ & $\begin{aligned} \chi^{2} & =22.856 \\
\rho & =0.541\end{aligned}$ & $\begin{array}{l}<0.001 \\
<0.001\end{array}$ \\
\hline \multicolumn{5}{|l|}{ Age (years) } \\
\hline 25-30 & $11(16.7)$ & $12(24.5)$ & & \\
\hline 31-35 & $14(21.4)$ & $15(30.6)$ & $\chi^{2}=3.864$ & 0.276 \\
\hline $36-40$ & $28(42.4)$ & $13(26.5)$ & $\rho=0.131$ & 0.161 \\
\hline 41-45 & $13(19.7)$ & $9(18.4)$ & & \\
\hline $\begin{array}{l}\text { Range of age (years) } \\
\left(\text { Mean } \pm \mathbf{S D}^{\mathbf{e}}\right)\end{array}$ & $\begin{array}{c}25-45 \\
(36.39 \pm 5.61)\end{array}$ & $\begin{array}{c}25-45 \\
(34.98 \pm 5.47)\end{array}$ & $t=1.304^{\mathrm{d}}$ & 0.195 \\
\hline \multicolumn{5}{|l|}{ Education } \\
\hline Under diploma & $11(16.7)$ & $5(10.2)$ & $\chi^{2}=1.207$ & 0.547 \\
\hline Diploma -Bachelor's degree & $30(61.2)$ & $35(53.0)$ & $\rho=-0.029$ & 0.754 \\
\hline Master's degree \& higher & $14(28.6)$ & $20(30.3)$ & & \\
\hline \multicolumn{5}{|l|}{ FBS $^{\mathrm{f}}(\mathrm{mg} / \mathrm{dl})$} \\
\hline$<200$ & $9(13.6)$ & 46 (93.9) & $\chi^{2}=72.701$ & $<0.001$ \\
\hline $200-400$ & $46(69.7)$ & $3(6.1)$ & $\rho=0.772$ & $<0.001$ \\
\hline$>400$ & $11(16.7)$ & $0(0.0)$ & & \\
\hline $\begin{array}{l}\text { Range of FBS level } \\
(\text { Mean } \pm \text { SD })\end{array}$ & $\begin{array}{c}119-488 \\
(321.98 \pm 91.2)\end{array}$ & $\begin{array}{c}115-217 \\
(165.96 \pm 29.48)\end{array}$ & $t=13.012$ & $<0.001$ \\
\hline \multicolumn{5}{|l|}{ Duration of diabetes (years) } \\
\hline$<5$ & $6(9.1)$ & $27(55.1)$ & $\chi^{2}=40.303$ & $<0.001$ \\
\hline $5-10$ & $34(51.5)$ & $22(44.9)$ & $\rho=0.592$ & $<0.001$ \\
\hline$>10$ & $26(39.4)$ & $0(0.0)$ & & \\
\hline $\begin{array}{l}\text { Range of diabetes duration (years) } \\
(\text { Mean } \pm \text { SD) }\end{array}$ & $\begin{array}{c}1-27 \\
(10.62 \pm 5.67) \\
\end{array}$ & $\begin{array}{c}1-8 \\
(4.03 \pm 2.9) \\
\end{array}$ & $t=8.663$ & $<0.001$ \\
\hline \multicolumn{5}{|l|}{ Treatment of vulvovaginitis } \\
\hline Antibiotics (with or without antifungals) & $62(93.9)$ & $14(28.6)$ & $\chi^{2}=53.915$ & $<0.001$ \\
\hline Antifungals (without antibiotic) & $4(6.1)$ & $35(71.4)$ & $\rho=0.683$ & $<0.001$ \\
\hline \multicolumn{5}{|l|}{ Severity of vulvovaginitis symptoms } \\
\hline Extensive \& severe & + & - & - & - \\
\hline Mild to moderate & - & + & - & - \\
\hline \multicolumn{5}{|l|}{ Incidence of vulvovaginitis in patients (in a year) } \\
\hline 1 & - & + & & \\
\hline$>1$ & + & - & & \\
\hline Corticosteroids & No & No & - & - \\
\hline Estrogen contraceptives & No & No & - & - \\
\hline Pregnancy & No & No & - & - \\
\hline Other diseases & No & No & - & - \\
\hline
\end{tabular}

aNumber $(\%)$

${ }^{\mathrm{b}} \mathrm{Chi}$-square
eStandard deviation

${ }^{\mathrm{f}}$ Fasting blood sugar level

\section{DISCUSSION}

With the increase of antifungal-resistant NAC species in recent years, the RVVC has become a significant health threat to women, especially those with diabetes [2, 14]. However, the data on the prevalence of RVVC caused by NAC species among diabetic women is not much, as most studies were more focused on C. albicans and non-recurrent $\operatorname{VVC}[7,9]$.

In our study, the prevalence of RVVC (57.4\%) was higher than VVC $(42.6 \%)$ in diabetic women, while in Brazil the prevalence of VVC and RVVC in diabetic women was the same and VVC was of a higher prevalence in non-diabetic women [23]. In other studies on nondiabetic patients, in Tehran (Iran) and Indonesia, RVVC showed a lower incidence, whereas in Zahedan (Iran) the rate of RVVC was more than VVC $[8,18,19]$. Our findings also showed that the number of patients infected simultaneously with two species was higher in RVVC group than those in VVC group, although the total percentage of single-species infections $(\mathrm{VVC}=40.9 \%$ \& $\mathrm{RVVC}=50.4 \%$ ) was higher than double-species ones (VVC $=1.7 \%$ \& $\mathrm{RVVC}=7 \%$ ) in both groups. In India and Egypt, vulvovaginal candidiasis with one species was also more prevalent [24, 25]. However, in Tehran, the frequency of multiple-species infections was the same in both VCC and RVVC groups [18]. In Sari, the rate of multiple infections was lower in VVC group [12].

In the present study, the NAC species in RVVC group had a higher frequency than the VVC group. Besides, $C$. glabrata was the most abundant NAC species, and its frequency in comparison to $C$. albicans in RVVC group was significantly higher than the VVC group $(P<0.001)$. 
Therefore, in RVVC group, the number of diabetic patients infected with NAC species compared to $C$. albicans was significantly higher than VVC group $(P<0.001)$, which was similar to the findings in diabetic women in Brazil and nondiabetic women in Urmia [5, 23]. However, in a similar study in Sari (Iran), the frequency of NAC species in VVC group was higher than RVVC group [12]. Other reports from Nigeria [13, 15], India [3, 25, 26], Iraq [17], and Burkina Faso of Africa [27] also revealed a higher prevalence of NAC species compare to $C$. albicans among diabetic and non-diabetic women. On the contrary, in diabetic patients of Yemen [29], Kermanshah (Iran) [30], and some non-diabetic patients with VVC in Iran and other countries, the prevalence of NAC species was less than $C$. albicans [10, 20, 25, 31, 32]. However, in non-diabetic women of America and Brazil, and diabetic women of Egypt, the ratio of NAC species and $C$. albicans was equal [7, 16, 28].

Some studies have reported lower rates of $C$. glabrata compared to $C$. krusei [26, 32], $C$. tropicalis [3,5] and $C$. parapsilosis [12], while our results and other studies in Iraq and Egypt $[15,17]$ demonstrated $C$. glabrata as the most prevalent species in diabetic and non-diabetic women. High prevalence of $C$. glabrata was also reported in other countries among diabetic [16, 29, 30] and non-diabetic women [25, 27, 32], which indicate an increasing trend in the prevalence of infections caused by this species. In China, during an eight-year study, the prevalence of $C$. glabrata increased from $10.6 \%$ to $21.7 \%$, while $C$. albicans declined from $82 \%$ to $77.2 \%$ [10].

Recurrence of severe vulvovaginitis symptoms depends on many predisposing factors. In the current study, the contributing factors were studied based on the data registered in the questionnaires. All women were almost of the same socioeconomic status, were not pregnant and had not taken corticosteroids and estrogen contraceptives. In both groups, the majority of cases $(n=41)$ were among women aged 36-40 years with a high school diploma or a bachelor's degree $(n=65)$. Some studies have reported the highest vulvovaginitis prevalence in the age range [24, 27] and education level [33] similar to our results. In India, Nigeria, and Sari (Iran), the highest incidence was in the age range 20-35 years [1, 12, 34], and in Yemen, Nepal, and Ethiopia, the women with the educational level of illiterate, primary and high school showed the highest prevalence rate [29, 31, 32]. Our results also showed no significant relationship between the incidence of infection and the age or education of the patients $(P>0.05)$. In Ethiopia and Malaysia, age and education were not significantly correlated with the incidence of vulvovaginitis $[32,35]$, while in Yemen and China, the relationship was significant [29, 33].

In the current study, high FBS levels and long-term diabetes, the two most important contributing factors, were significantly correlated $(P<0.001)$ with the RVVC prevalence. Many reports from Iran and other countries have indicated a significant relationship between the recurrence of severe infection and FBS levels [19, 24, 29, 34, 36] as well as long-term uncontrolled diabetes [29].
Therefore, diabetes mellitus can be considered as one of the most important predisposing factors for vulvovaginitis, especially in RVVC group $[1,23,36]$. Because uncontrolled hyperglycemia potentially reduces the adhesion, chemotaxis, and phagocytosis of pathogendestroying leukocytes [16, 26]. Increased glucose in the vulvovaginal tissue along with a decreased $\mathrm{pH}$ can increase the capability of adhesion, colonization, and invasion of Candida species to the tissues [16, 26].

In RVVC group that most women were taking antibiotics (with or without antifungal), there was a significant correlation between the severity of the infection and the antibiotics usage. Similar findings are available from Iran (Zahedan), Egypt, and Iraq [19, 24, 36], whereas other studies in Iran (Shahrekord) and Nepal reported no relationship between them $[31,37]$.

Interviewing the patients revealed that the diagnosis of vulvovaginitis and drugs prescription was merely based on clinical examinations and routine laboratory tests. Azitromycin along with another antibiotic such as clindamycin, metronidazole, tinidazole or triple sulfa (for bacterial vaginosis and trichomoniasis) were commonly prescribed following the initial clinical examination to most patients with severe clinical symptoms. Following recurrence of more acute symptoms, antifungals, e.g. clotrimazole, miconazole, or fluconazole were prescribed along with two of these antibiotics. Candida albicans is one of the sensitive species to clotrimazole, miconazole, and fluconazole, while most NAC species, particularly $C$. glabrata, have shown an intrinsic and acquired resistance to a vast range of azoles [25, 27, 37]. Treatment failures might be due to the inaccurate diagnosis of the causative agent, as several pathogens may cause vulvovaginitis with similar clinical symptoms. Many studies have reported simultaneous infection with different Candida species [12, $18,23,24]$, or coinfections of yeasts, bacteria, and Trichomonias vaginalis $[1,6]$. In China, the rate of vulvovaginitis caused by mixed infections of Candida and bacteria was higher than Candida infection alone [33]. The use of broad-spectrum antibiotics for an extended time might reduce the vaginal indigenous microbiota, and led to a remarkable increase in the colonization of drug-resistant NAC species and recurrence of the disease [7, 24, 28, 37]. The high prevalence of RVVC caused by C. glabrata in our study might be linked with this issue.

In our study, CHROMagar Candida medium was a useful method for primary isolation and identification of Candida species based on phenotypic features. However, it was time-consuming $(48-72 \mathrm{~h})$ and lacked the reliable sensitivity to discriminate the species by the color of colonies, especially in mixed infection. For example, the differentiation of some $C$. albicans colonies from dark green colonies of $C$. dubliniensis, or pale-dark pink/purple C. glabrata colonies from those of species with a similar color were ambiguous, which was in agreement with other studies reporting the same challenge [11, 12, 38, 39].

PCR technique along with proper restriction enzymes, has shown to be a reliable method to differentiate Candida species $[11,19,22]$. Some studies demonstrated that some 
restriction enzymes such as HepaIII, DdeI, and BfaI did not have a reliable discriminating power to identify Candida species, probably due to inaccessibility of ITS1-ITS4 sequences $[40,41]$. Similar to previous studies [11, 19, 22, 41, 42], we could identify Candida species by PCR-RFLP using the efficient $M s p I$ and $A v r I I$ restriction enzymes.

Vulvovaginal candidiasis is still a prevalent infection, especially among diabetic women. Regarding the significant relationship between recurrent VVC and longtime hyperglycemia and antibiotics usage, controlling FBS and avoiding excessive antibiotics can be helpful in the treatment of infection. Besides, the significant frequency of C. glabrata in comparison with $C$. albicans in RVVC group and its resistance to treatment with common antifungals can emphasize the importance of accurate diagnosis of the causative agent using molecular techniques.

\section{ACKNOWLEDGMENT}

This study is a part of the Ph.D. thesis in Mycology at Islamic Azad University of Science and Research Branch. The study was conducted at Islamic Azad University, Shahr-e-Qods Branch and Pasteur Institute of Iran. The authors are grateful to the staff of the Physiology and Department of Pharmacology, Pasteur Institute of Iran and the Genetic and Microbiology laboratories at the Islamic Azad University, Shahr-e-Qods Branch. We also thank Professor Ahmad Moin Taghavi for supervising the statistical calculations.

\section{CONFLICT OF INTEREST}

The authors declare that there are no conflicts of interest associated with this manuscript.

\section{REFERENCES}

1. Gandhi TN, Patel MG, Jain MR. Prospective study of vaginal discharge and prevalence of Vulvovaginal candidiasis in a tertiary care hospital. Int J Cur Res Rev. 2015; 7 (1): 34-38.

2. LemaVM. Recurrent Vulvo-Vaginal Candidiasis: Diagnostic and Management Challenges in a Developing Country Context. Obstet Gynecol Int J. 2017; 7 (5): 00260.

3. Kalia N, Singh J, Sharma S, Kamboj SS, Arora H, Kaur M. Prevalence of Vulvovaginal Infections and Species Specific Distribution of Vulvovaginal Candidiasis in Married Women of North India. IntJ CurrMicrobiol App Sci. 2015; 4 (8): 253-266.

4. Workowski KA, Bolan GA. Sexually transmitted diseases treatment guidelines. Morb Mortal Wkly Rep. 2015; 64 (RR3): $1-137$.

5. Diba K, Namaki A, Ayatolahi H, Hanifian H. Comparison of biochemical and molecular methods for the identification of Candida species causing vulvovaginal candidiasis and recurring vulvovaginal candidiasis. Iran J Med Microbiol. 2014; 8 (3): 4550 [In Persian].

6. Marschalek J, Farr A, Kiss H, Hagmann M, Göbl CS, Trofaier ML, et al. Risk of Vaginal Infections at Early Gestation in Patients with Diabetic Conditions during Pregnancy: A Retrospective Cohort Study. Plos One. 2016; 11 (5): e0155182.
7. Mintz JD, Martenz MG. Prevalence of Non-albicans Candida Infections in Women with Recurrent Vulvovaginal symptomatology. Adv Infect Dis. 2013; 3: 238-242.

8. Arfiputri D.S, Hidayati A.N, Handayani S, Ervianti E. Risk Factors of Vulvovaginal Candidiasis in Dermato-Venereology Outpatients Clinic of Soetomo General Hospital, Surabaya, Indonesia. Afr J Infect Dis. 2018; 12 (S): 90-94.

9. BlosteinF, Levin-Sparenberg E, Wagner J, Foxman B. Recurrent vulvovaginal candidiasis. Annals of Epidemiology. 2017; 27: 575e582.

10. Wang FJ, Zhang D, Liu ZhH, Wu WX, Bai HH, Dong HY. Species Distribution and In Vitro Antifungal Susceptibility of Vulvovaginal of Candida species Isolates in China. Chin Med J. 2016; 129 (10): 1161-65.

11. Elfeky DS, Gohar NM, EL-Seidi EA, Ezzat MM, AboElew SH. Species identification and antifungal susceptibility pattern of Candida isolates in cases of vaginal candidiasis. Alexandria $\mathbf{J}$ Med. 2016; 52: 269-77.

12. Hedayati MT, Taheri Z, Galinimoghadam T, Aghili SR, Yazdani JG, Mosayebi E. Isolation of Different Species of Candida in Patients With Vulvovaginal Candidiasis From Sari, Iran. Jundishapur J Microbiol. 2015; 8 (4): e15992.

13. Jimoh O, Hannah I, Yakubu SE, Ankuma SJ, Olayinka AT. Prevalence and Speciation of Non-albicans Vulvovaginal Candidiasis in Zaria. J Nat Sci Res. 2016; 6 (2): 51-56.

14. Bonifaz A, Armas-Vázquez A, Tirado-Sánchez A. Fungal Infections in Diabetics. Dermatology and Diabetes. 2017; 117 132.

15. Adebiyi OE, Oluwadun A, Daniel OJ, Oritogun RS, Fasanmade AA. Prevalence of Vulvovaginal Candidiasis Among Women with Diabetes mellitus in Ibadan, Oyo State, Nigeria. Ann Health Res. 2016; 21 (2).

16. Bassyouni RH, Wegdan AA, Abdelmoneim A, Said W, AboElnaga F. Phospholipase and Aspartyl Proteinase Activities of Candida Species Causing Vulvovaginal Candidiasis in Patients with Type 2 Diabetes Mellitus. J Microbiol Biotechnol. 2015; 25 (10): 1734-41.

17. MohammedAB, Ali JH, Abdullah SK. Identification of Candida spp. isolated from vaginal swab by phenotyp.ic methods and multiplex PCR in Duhok, Iraq. Int J Res Med Sci. 2015; 3 (11): 3211-6.

18. Mahmoudi Rad M, Zafarghandi AS, Amel Zabihi M, Mirdamadi Y, Rahbarian N, Abbasabadi B, et al. Identification of Candida species associated with vulvovaginal candidiasis by Multiplex PCR method. Tehran Univ Med J. 2009; 67 (9): 623-8 [In Persian].

19. Fouladi B, Yadegari M, Rajabibazl M, Fazaeli A, Hashemzadeh MC. Identification of Candida Species in Patients with Vulvovaginitis Presenting Different Clinical Symptoms. J Zanjan Univ Med Sci. 2015; 23 (98): 53-67 [In Persian].

20. Mohammadi R, MirhendiH, Yadegari MH,ShadziSh, Jalalizand N. Identification and Frequency of Candida Species in Patients with Different Forms of Candidiasis in Isfahan, Using PCR-RFLP Method. J Isfahan Med Sch. 2011; 29 (133): 336-43 [In Persian]. 
21. Korabecna M. The Variability in the Fungal Ribosomal DNA (ITS1, ITS2, and $5.8 \mathrm{~S}$ rRNA Gene): Its Biological Meaning and Application in Medical Mycology. Communicating Current Research and Educational Topics and Trends in Applied Microbiology A. Méndez-Vilas (Ed.) 2007; 1: 783-7.

22. Mirhendi H, Makimura K, Zomorodian K, Meeda N. Differentiation of Candida albicans and Candida dubliniensis using single-Enzyme PCR-RFLP Method. Jpn J Infect Ois. 2005; 58: 235-37.

23. Gunther LSA, Martins HPR, Gimenes F, Abreu ALP, Consolaro MEL, Svidzinski TIE. Prevalence of Candida albicans and non-albicans isolates from vaginal secretions: comparative evaluation of colonization, vaginal candidiasis and recurrent vaginal candidiasis in diabetic and non-diabetic women. Sao Paulo Med J. 2014; 132 (2): 116-120.

24. Fattouh M, Nasr El-din A, Badawy A, Nour El-din M, Ahmed H. Antifungal Susceptibility Pattern and Species Distribution of Candida Isolates from Patients with Vulvovaginal Candidiasis. Int J Adv Res. 2015; 3 (5): 1376-86.

25. Kalaiarasan K, Singh R, Chaturvedula L. Fungal Profile of Vulvovaginal Candidiasis in a Tertiary Care Hospital. J Clin Diagn Res. 2017, 11(3): DC06-DC09.

26. Shrivastav V.K, Shukla D, Shrivastav A, Jana A.M. Prevalence of vaginal candidiasis in diabetic women of Madhya Pradesh, India. Int J Curr Microbiol App Sci. 2015; 4(5): 834846.

27. Sangaré I, Sirima C, Bamba S, Zida A, Cissé M, Bazié WW, et al. Prevalence of vulvovaginal candidiasis in pregnancy at three health centers in Burkina Faso. J Mycol Med. 2018; 28 (1): 186-192.

28. Goulart LS, Santiago EF, Ramon JL, Moura SV, Silva AR, Silva IF, et al. Species distribution and antifungal susceptibility to vulvovaginal Candida spp. in southern Mato Grosso State, Brazil. J Bras Patol Med Lab. 2016; 52(4): 233-237.

29. Al-mamari A, Al-buryhi M.M, Al-hag S. Species-specific prevalence of vaginal candidiasis with type 1 and type 2 diabetes mellitus among women in Sana'a city. J Chem Pharm Res. 2013; 5 (8): 217-224.

30. Faraji R, Rahimi MA, Rezvanmadani F, Hashemi M. Prevalence of vaginal candidiasis infection in diabetic women. African J Microbial Res. 2012; 6 (11): 2773-8.
31. Yadav K, Prakash S. Prevalence of Vulvovaginal Candidiasis in Pregnancy. Glob J Med Med Sci. 2016; 4 (1): 108-116.

32. Bitew A, Abebaw Y. Vulvovaginal candidiasis: species distribution of Candida and their antifungal susceptibility pattern. BMC Women's Health. 2018; 18: 94.

33. Wang H, Huang Z, Wu Z, Qi X, Lin D. An epidemiological study on vaginitis in 6,150 women of reproductive age in Shanghai. New Microbiologica. 2017; 40 (2): 113-8.

34. Pondei K, Jeremiah I, Lawani E, Nsikak E. The Prevalence of Symptomatic Vulvovaginal Candidiasis and Trichomonas vaginalis Infection and Associated Risk Factors among Women in the Niger Delta Region of Nigeria. ISRR. 2017; 5 (2): 1-10.

35. Sopian LL, Shahabudin S, Ahmed MA, Lung LTT, Sandai D. Yeast Infection and Diabetes Mellitus among Pregnant Mother in Malaysia. Malays J Med Sci. 2016; 23 (1): 27-34.

36. Alsharifi E.A, Epidemiology of vaginal candidiasis among pregnant women attending Tikrit teaching hospital/Iraq. J Fac Med Baghdad. 2017; 59 (4): 321-324.

37. Habibian R, Jafarzadeh L, Shahriari K. Investigating the relationship between recurrent candidiasis with predisposing factors and symptoms of disease. J Shahrekord Univ Med Sci. 2013; 15 (5): 38-46 [In Persian].

38. Devi LS, Maheshwari M. Speciation of Candida Species Isolated From Clinical Specimen By CHROMagar and Conventional Method. Int J Sci Res Pub 2014; 4 (3): 1-5.

39. Zhai Y, Liu J, Zhou L, Ji T, Meng L, Gao Y, et al. Detection of Candida species in pregnant Chinese women with a molecular beacon method. J Med Microbiol 2018; 67 (4): 1-7.

40. Williams DW, Wilson MJ, Lewis MA, Pots AJ. Identification of Candida species by $\mathrm{PCR}$ and restriction fragment length polymorphism analysis of intergenic spacer region of ribosomal DNA. J Clin Microbiol. 33: 2476-9.

41. Mirhendi H, Makimura K, Khoramizadeh MR, Yamaguchi H. A One-Enzyme PCR-RFLP Assay Identification of Six Medically Important Candida Species. J Mycol Méd. 2006; 47 (3): $222-5$.

42. Samiei M, Moaseni M, Ajudanifar H, Karimi N. Molecular identification and antifungal susceptibility of Candida albicans isolated from vulvovaginal candidiasis. Int J Mol Clin Microbiol 2014; $1: 383-8$. 